\title{
RE-ESTRUCTURACIÓN CAPITALLSTA: PRECARIEDAD LABORAL Y RESISTENCIA. LA PROTESTA DE LOS MINEROS DEL COBRE EN CHILE
}

\section{María Fernanda Hughes \\ Universidad de Buenos Aires - Argentina}

Resumen: El artículo presenta una investigación de campo acerca de la protesta laboral de los trabajadores del cobre, sector de la producción fundamental para la economía chilena. Una de las formas que la gestión neoliberal ha aplicado al trabajo es la subcontratación o "tercerización". A pesar de toda una batería de obstáculos objetivos y subjetivos para organizarse, una parte de los trabajadores se han sindicalizado por fuera y paralelamente a las estructuras sindicales tradicionales. No sólo lo han hecho, sino que hicieron visible la conflictividad inherente al modelo neoliberal que Chile ha presentado como la experiencia "más exitosa".

Palabras clave: minería cobre, protesta laboral, subcontratación, trabajo.

Abstract: This article presents a field research about the work protest of the copper industry workers, which is a fundamental productive sector in the Chilean economy. One of the forms the neoliberal management has applied to the work structure is subcontracting or outsourcing. In spite of a great number of objectives and subjectives obstacles, part of the workers subcontracted has unionized in a parallel way, outside the traditional union structures. Not only they did so, but became in one of the protagonists of the social protest in Chile, making visible the social unrest inherent in the neoliberal model, from which the Chilean Case has been presented as its "most successful" experience.

Keywords: mining, subcontracting, work, work protest.

\section{Introducción}

Con el inicio de la dictadura en Chile la política económica experimenta una profunda transformación. Desde ese momento, funcionarios de gobiernos, 
tanto dictatoriales como democráticos, repitieron de manera insistente una serie de propuestas que se presentaban como las grandes verdades para obtener el éxito económico: el mercado lo resolvería todo de la mejor forma posible; el estado es esencialmente inepto e ineficiente y debe retirarse de la actividad económica. Los costos sociales que provocarían las reformas, se suponía, serían transitorios y breves, ya que, teóricamente, las reformas estructurales darían lugar a una expansión significativa de la inversión, el crecimiento económico, el empleo y las remuneraciones. Se sostuvo con mucha frecuencia, que antes de distribuir la riqueza (antes de mejorar la distribución), se debía producir el crecimiento económico.

Desde fines de los ' 60 y comienzos de los '70, se había producido una disminución de la tasa de ganancia. ${ }^{1}$ Recomponer a esta última requería transferir el poder acumulado en el campo del trabajo al campo del capital. Es entonces que se desata la ofensiva contra los trabajadores y sus salarios, contra el gasto estatal en tanto restaba a los ingresos de los empresarios, y contra las formas de gobierno que limitaban la acumulación. Se imponía para el Capital el establecimiento de un nuevo orden. La Dictadura Militar se constituyó en la primera estrategia de disciplinamiento social para poder aplicar "exitosamente” las reformas. De esta forma, se silenció el conflicto social por la redistribución de la renta en Chile.

La recuperación de la crisis significa para el capital, sobre todo, la reafirmación de su autoridad, su derecho a administrar y a mandar. Es dentro de este contexto -en el contexto de la crisis y no debido a elecciones o a alguna batalla de ideas autónoma- que hay un viraje de la estrategia capitalista hacia ideas más autoritarias, hacia una dirección empresarial más autoritaria. El creciente autoritarismo no resulta de los éxitos de la Nueva Derecha: al contrario, su éxito es el resultado de las presiones hacia un mayor autoritarismo. Para el capital, la reafirmación de la autoridad es la precondición de todo lo demás. (Holloway, 1987, p. 52).

Las políticas puestas en práctica, deterioraron la situación social. Si observamos la situación laboral, constatamos un drástico deterioro de su calidad: se incrementaron la informalidad y la precariedad laboral. La desigual distribución de los ingresos sigue siendo un rasgo sobresaliente de la estructura

1 Expresión porcentual de la relación entre las ganancias y los capitales invertidos. 
económica y social, reflejándose en los altos niveles de desigualdad social y el abismal distanciamiento entre ricos y pobres. ${ }^{2}$

La precarización del trabajo se ha ido produciendo a partir de las profundas transformaciones impuestas por la Dictadura Militar. Para ello, fueron determinantes la liberalización de las normas de contratación laboral ${ }^{3}$ como así también el proceso de fragmentación vertical de las empresas en unidades económicas más pequeñas y eslabonadas horizontalmente. Los cambios en la organización y funcionamiento, que fraccionan la producción y a las empresas en múltiples unidades económicas, que gracias a la innovación tecnológica, permite que se articulen sólidamente y organicen en un centro sin importar dónde esas unidades estén operando materialmente.

En un contexto de elevadas tasas de desempleo, ${ }^{4}$ estas modificaciones facilitaron al capital óptimas condiciones para atomizar a los trabajadores y para reducir a su mínima expresión la organización sindical. La externalización, la fragmentación de las empresas y la creación de nuevas articulaciones entre ellas, respondería principalmente a la "inserción” de Chile en la "economía global”. Pero no hay que desconocer o subestimar el atractivo de debilitar a las organizaciones sindicales al disgregar a los trabajadores como así también la facilitación de violar las conquistas sindicales. De esta forma se reducen costos al pagar salarios inferiores, desatendiendo el cumplimiento con los beneficios sociales y/o los aportes a la seguridad social. En este marco, se dificulta la existencia de una organización sindical fuerte, ya que al reducir al mínimo posible el número de trabajadores permanentes y los subcontratados y/o temporarios estar en una situación de inestabilidad constante, la organización se torna mucho más difícil.

2 Según informe de abril de 2011 de la OCDE, del que Chile es miembro, el 18,9\% de la población es pobre; y el coeficiente de Gini es de 0,50. Hace por lo menos 25 años se mantiene este nivel de desigualdad, lo que lo transforma en un problema estructural y no en parte de un ciclo.

3 Nos referimos al Plan Laboral de 1979 y al Código del Trabajo. La subcontratación fue aún más estimulada con la derogación de la Ley $\mathrm{N}^{\circ} 16.757$ de 1979, ampliando las funciones de los subcontratistas a todas las áreas de las empresas, incluyendo las labores inherentes a la producción principal y permanente de la empresa como también a las labores de reparación o manutención habituales.

4 En 1982, la tasa de desempleo habría llegado al 30\%. (Cortés Morales, 2009). Chile según estudios de la CEPAL, fue el país de América Latina más afectado en la crisis de inicios de los años 80 . El PIB cayó en $14 \%$, la producción industrial en 23\% y la desocupación, según CIEPLAN, alcanzó el 30\%. Esta crisis ha sido caracterizada como ‘el colapso económico y financiero de 1982 y 1983’ por académicos chilenos (Caputo, 2008b).

Horizontes Antropológicos, Porto Alegre, ano 19, n. 39, p. 99-124, jan./jun. 2013 
La desregulación fue impuesta poco después del Golpe de Estado de $1973 .{ }^{5}$ El trabajo no regulado (“flexibilizado") posibilita la incorporación laboral al proceso productivo sin compromisos para el Capital, descargando en el trabajador la responsabilidad de su reproducción permanente.

La tendencia a la subcontratación y a la informalización del empleo se ha hecho manifiesta en todos los sectores productivos, pero sobre todo en los más directamente ligados a los éxitos del modelo: la minería, la pesca, la industria forestal y la fruticultura. (Salazar; Pinto, 1999, p. 185).

Ante el fenómeno del desempleo o de la reducción del personal, los trabajadores pierden su capacidad de respuesta y negociación de manera brutal. Dichos fenómenos violentan la vida de los sujetos, quienes se ven obligados a aceptar cualquier trabajo, sin importar las condiciones, al dejar de funcionar los mecanismos de regulación laboral: es la vivencia cotidiana, continua, de la amenaza del despido. Es la absoluta subordinación del trabajador, ya que la pérdida de la capacidad de negociar colectivamente lo deja en una absoluta indefensión, aceptando peores condiciones de trabajo para no quedar desempleado. Es en ese momento cuando emerge silenciosamente la figura del "subcontratista” en Chile.

\section{El terrorismo de Estado: condición necesaria para la transformación}

De Chile a Irak, la tortura ha sido el socio silencioso de la cruzada por la libertad del mercado global.

Klein (2007, p. 39).

Con la dictadura pinochetista, se inicia un período que ha sido llamado como “contrarrevolución neoliberal” (Agacino, 2008), Chile se transforma rápidamente en una suerte de "laboratorio mundial” del llamado neoliberalismo, varios años antes que la Gran Bretaña de Margareth Thatcher o que los EEUU de Ronald Reagan.

5 Recordemos que fueron eliminadas las negociaciones colectivas, suspendido el derecho a la huelga, prohibida la actividad sindical y abandonado el sistema de negociación salarial vigente hasta ese momento. 
Milton Friedman (1966), el San Juan Bautista del llamado neoliberalismo, proponía reducir las funciones del Estado a proteger nuestras libertades de los enemigos del exterior y del interior, defender la ley y el orden y garantizar los contratos privados.

La doctrina del Shock, tal como la nomina Klein (2007, p. 27), consiste según Friedman que "sólo una crisis -real o percibida- da lugar a un cambio verdadero”, adjudicándole al gurú de Chicago la función básica que debía desarrollar con sus seguidores; políticas alternativas hasta que "lo políticamente imposible se vuelva políticamente inevitable”.

El llamado neoliberalismo había devenido en sentido común de la época. Junto a la acelerada acumulación y concentración de la riqueza, monopoliza el poder político, económico y comunicacional, controlando también la orientación y gestión del conocimiento para reproducir la hegemonía. Holloway (1987, p. 50) refiriéndose a la posición que adoptaron muchos intelectuales ante el triunfo del capital representado en el neoliberalismo:

En apariencia, la nueva realidad no consiste en el conflicto permanente entre capital y trabajo. Es una realidad que emerge y no confronta clases, sino "gente”. Las clases no tienen lugar en este mundo: el cambio no se produce a través de la incesante lucha de clases sino a través de la democracia y ganando el apoyo de la opinión pública. [...] La gente de esta nueva realidad es toda gente razonable y gentil.

El terrorismo de Estado se constituyó en la condición indispensable para lograr el disciplinamiento social e inducir el camino de las reformas estructurales. Desde inicios de la década del '70, por medio de la Dictadura Militar, la sociedad chilena -que parte de una matriz comparativamente más clasista y polarizada que la argentina- ha sufrido duros procesos de disciplinamiento para ser sometida al régimen del orden. Dicho disciplinamiento se asienta sobre la derrota previa de la clase obrera y los sectores populares. El Terrorismo de Estado que se instauró gracias a la colaboración activa de la CIA, permitió imponer los planes económicos del gran capital y el imperialismo. Ya en 1974 la dictadura promulga el Estatuto del Inversionista Extranjero, iniciando la transformación de la estructura de la propiedad a favor del capital foráneo. La eliminación de las conquistas laborales, la proscripción de la CUT (Central Única de Trabajadores) y el aparato represivo actuando constantemente serán 
las bases del disciplinamiento y la derrota. Los sucesivos gobiernos de la Concertación (Concertación de Partidos por la Democracia) no sólo no cuestionaron las reformas establecidas por la dictadura, sino que las mantuvieron y profundizaron, consolidando el orden económico "neoliberal”, borrando, anulando o clausurando del horizonte de los trabajadores la perspectiva de cambio alternativo y la idea de revolución (Hughes, 2012). Petras (1988, p. 82) se refiere a los intelectuales que conformaron la Concertación, muchos de ellos exiliados que habían estado en estrecha relación con las corrientes liberales y social-demócratas vigentes, que, en relación a los estudios e investigaciones sobre la dictadura

encararon sus rasgos políticamente represivos y no sus vínculos económicos y militares con las élites de Europa Occidental y Estados Unidos; la violencia de Estado se analizó en términos de violaciones a los derechos humanos, no como expresión de dominio de clase, de la lucha de clases, de la violencia de clase; la base política que surgió de esos estudios planteó el tema como concepciones políticas enfrentadas, como conflicto entre la democracia liberal y la dictadura militar, la disociación deliberada de la estructura de clase del poder estatal fue justificada por la idea de que la esfera política era "autónoma" de la sociedad civil.

En todo este proceso, iniciado en los años de dictadura, lo que más nos interesa trabajar y destacar es lo que se refiere a los efectos que el mismo tuvo con respecto a los trabajadores. La maximización de las utilidades primó por sobre cualquier consideración de tipo social. Así, el sector laboral, que en los primeros años de la imposición del nuevo régimen económico fue arbitrariamente reprimido, luego fue disciplinado en los esquemas de la economía social de mercado, que a través del Código de Trabajo, institucionaliza la atomización de los trabajadores, permitiendo de esta manera la despiadada explotación de la mano de obra a través del régimen de tercerización que se origina a partir de 1978, provocando un fuerte deterioro en las condiciones de trabajo y en la calidad de vida de los obreros y de sus familias.

Con la llegada de la democracia, el nuevo gobierno de la Concertación, consolidó una política de Estado que otorga al llamado mercado la función principal en la asignación de los recursos productivos y al sector privado la propiedad de la mayoría de las empresas y servicios públicos, a la vez que se acentúa el modelo exportador de recursos naturales. 
Recordemos que es en la década de los ' 90 , cuando se presenta a Chile, dados sus logros macroeconómicos y sociales, ${ }^{6}$ como el ejemplo a seguir por los países de la región, imponiéndose la frase al hacer referencia al país de el milagro chileno.

Buscado como objetivo tanto por la gestión de Aylwin como por la de Frei, recién en 2003, durante la presidencia de Lagos, se firmó el Tratado de Libre Comercio entre Chile y Estados Unidos, entrando en vigencia el $1^{\circ}$ de enero de 2004. El TLC estableció algunas obligaciones recíprocas para ambos Estados, entre otras, se adoptaron compromisos recíprocos de reconocimiento, protección y difusión de derechos laborales considerados indispensables para que el libre comercio beneficiara también a los trabajadores y trabajadoras. Se acordó el compromiso recíproco de normar, fiscalizar y difundir algunos derechos laborales de amplio reconocimiento internacional: derecho a la asociación, derechos a organizarse y negociar colectivamente, prohibición de uso de trabajo forzoso, prohibición y eliminación de las peores formas de trabajo infantil y condiciones de trabajo aceptables relativos a salarios mínimos, horas de trabajo, seguridad y salud ocupacional. Estas no fueron más que formalidades asentadas en un papel, a las que la mayoría de los trabajadores nunca accedió (Hughes; Lischetti, 2012).

La forma adquirida por el proceso de apertura de la economía chilena condujo a una profunda modificación de su estructura productiva. Crece un sector exportador, basado en recursos primarios o de bajo valor agregado, mientras paralelamente la producción orientada al mercado interno es crecientemente reemplazada por productos importados. Los tratados de libre comercio tienden a acentuar esta tendencia, al igual que la disminución en el papel del Estado (Fazio; Parada, 2010, p. 97).

\section{La subcontratación: precarización del trabajo en Chile}

En Chile, la contratación de servicios con terceros y de mano de obra para actividades menores a través de un intermediario, no es una práctica reciente.

6 En 1990, el 38,6\% de la población, eran pobres no indigentes e indigentes (25,7\% y 12,9\% respectivamente). En 1998, esas cifras habían descendido a 21,7\% (16,1\% y 5,6\%). Fuente: Ministerio de Planificación y Cooperación (1999, p. 7). Sin embargo, la distribución del ingreso no había variado sustancialmente. 
Ya desde fines del siglo XIX, trabajadores del centro y del sur del país eran "enganchados" para trasladarlos al norte, donde se incorporaban al trabajo en las salitreras. Los intermediarios, conocidos como "enganchadores”, terminaban su actividad una vez que los trabajadores ingresaban al mundo del salitre. Durante gran parte del siglo XX, la intermediación fue una práctica marginal y reducida a unas pocas ramas de actividad. Sin embargo, en la actualidad, lo extraordinario de este fenómeno es su extensión y generalización a todas las ramas. La externalización de la producción y del trabajo en forma sistemática se habría producido desde mediados de los años ' 70 .

Estas formas de trabajo, que algunos autores agrupan bajo la denominación de "atípicas" quedan por fuera de los marcos que caracterizaban al asalariado "clásico": estabilidad laboral, acceso a la seguridad social y jornada laboral continua. Según Castel (1997), la sociedad salarial es aquella cuya forma de organización social se sustenta en la adquisición de los derechos sociales a través del trabajo en su forma de relación salarial. Esta implica el establecimiento de un contrato entre el empleador y el individuo en tanto fuerza de trabajo, siendo el Estado el garante de lo pactado a través de la negociación colectiva realizada entre el empleador y los trabajadores sindicalizados. Los atributos que caracterizaban al estatuto del trabajador asalariado ubicaban y clasificaban al individuo en la sociedad, en detrimento de los otros sostenes de identidad. De modo tal que vemos que el trabajo capitalista se erige en principio organizador de nuestras vidas. La sociedad salarial aseguraba derechos, daba acceso a prestaciones fuera del trabajo y posibilitaba una participación ampliada en la vida social: consumo, vivienda, educación, ocio (Castel, 1997). Las organizaciones sindicales habían logrado obtener leyes que protegían a los trabajadores, asegurándoles el derecho a la estabilidad en el empleo y niveles salariales relativamente altos al compararlos con etapas anteriores. $\mathrm{La}$ precarización laboral sería una respuesta del capital ante la crisis de acumulación del capitalismo en la década del '70.

La relación salarial implicaba un empleador y su contracara, el empleado: uno no existe sin el otro. Esta relación se rompe al intervenir terceras y cuartas personas y dificulta establecer cuáles son las partes de la relación.

Asimismo, la externalización debilita y divide a las organizaciones sindicales: por un lado, las relaciones se atomizan y se dispersan; por otro, se hace cada vez más difusa y confusa la figura del empleador. Los trabajadores se dividen en un "nosotros”, "los internos”, "los de planta”, y los “otros”, "los de 
afuera", "los subcontratados". A esto, se debe sumar que resulta sumamente difícil construir vínculos con y entre trabajadores transitorios, y en muchos casos, la administración de la empresa coloca todos los obstáculos posibles para impedir que se produzcan.

Como ya mencionamos, la extensión, generalización y adquisición de la externalización o tercerización, ${ }^{7}$ se ha ido produciendo a partir de las profundas transformaciones impuestas durante el gobierno de la Dictadura Militar.

La "nueva organización industrial” se concretó desde muy temprano a través de una centralización horizontal del capital y de la fragmentación productiva. La centralización horizontal, como forma de control conglomerante de la propiedad, reconfiguró al segmento dominante del empresariado dando paso a "grupos económicos" con inversiones transversales, es decir, interesados cada vez más en la "acumulación en general" y menos en un "valor de uso" o rama específicos. La fragmentación productiva, por su parte, bajo la forma de externalización de funciones o subcontratación, modificó la demografía empresarial generando una estructura muy heterogénea que vinculó orgánicamente a firmas medianas y pequeñas -e incluso micro-empresas y trabajadores a domicilio- con los grandes conglomerados controladores de los procesos de acumulación. (Agacino, 2008).

La externalización adquiere diferentes modalidades. Puede ser geográfica, realizándose las actividades fuera del espacio de la empresa contratante, o sólo jurídica, como cuando las actividades se realizan dentro del recinto de la empresa contratante pero está a cargo de otra entidad jurídica. Los trabajadores subcontratados pueden prestar sus servicios dentro o fuera de las instalaciones de la empresa contratante (o usuaria).

Por lo general, tienden a externalizarse procesos que implican un alto contenido manual, que requieren un gran esfuerzo físico, que conllevan una acción repetitiva, o aquellas labores que exponen a los trabajadores a un mayor riesgo.

De acuerdo al objeto de subcontratación se puede distinguir entre dos ejemplos básicos; a) cuando se transfiere a un tercero la producción de bienes

\footnotetext{
Tercerización alude al proceso por el cual una determinada actividad deja de ser desarrollada por los trabajadores de una empresa y es transferida a otra empresa, a una "tercera”. La actividad que antes se desarrollaba internamente, dentro de la empresa, pasa a realizarse en el exterior de la misma, se “externaliza”.
}

Horizontes Antropológicos, Porto Alegre, ano 19, n. 39, p. 99-124, jan./jun. 2013 
o la prestación de servicios o bien b) cuando se le encarga la provisión de trabajo, concretamente, trabajadores. A esta última forma se la ha denominado "suministro de personal".

En el caso a) la subcontratación refiere a las relaciones que se establecen entre una empresa mandante o principal que encarga a otra la producción de partes, etapas o partidas completas de bienes o la prestación de un servicio que puede ser parte central, anexa o complementaria del proceso productivo. O sea, una empresa, dueña de una obra o faena, contrata a otra empresa para que realice a su cuenta y riesgo, con sus propios trabajadores, un determinado trabajo o servicio. Las relaciones que se establecen son comerciales, entre empresas, donde una vende y la otra compra servicios o etapas completas del proceso productivo. La relación laboral se establece entre la empresa contratista y sus trabajadores, a quienes se los suele nominar trabajadores de contratistas, subcontratados o contratistas. La compañía mandante no forma parte de la relación. La figura del empleador es una: aquel con quien el trabajador suscribe un contrato y de quien pasa a estar bajo subordinación y dependencia.

Distintas son las relaciones que se establecen en el caso b); esto es, cuando se produce la subcontratación de trabajo, de personas, o "suministro de personal”. Bajo esta modalidad, se relaciona la empresa usuaria con una empresa suministradora, la que presta el servicio de suministrar trabajadores. Si la empresa contratista no se limita sólo a la colocación de trabajadores en puestos de trabajo desentendiéndose a partir de ese momento de la relación laboral, como ocurría en el caso de los “enganchadores”, sino que mantiene con ellos la relación, cuestiona la forma clásica entre trabajador y empleador ya que intervienen tres partes, dando lugar a relaciones triangulares de trabajo: por un lado los trabajadores suministrados; por otro el suministrador y finalmente el usuario que es quien define los contenidos del trabajo, dirige y supervisa su ejecución. En esta relación triangular, la empresa contratista mantiene todas las obligaciones laborales legales con el trabajador, pero es la empresa usuaria la que conserva el poder de ordenar y organizar el modo, tiempo y lugar en que se realizará el trabajo. El trabajador desempeña sus tareas en las instalaciones de la empresa usuaria, quien además le proporciona los medios de trabajo.

El usuario en este caso no sólo compra trabajo sino que también produce el desdibujamiento del trabajador como sujeto de relación laboral. El usuario o contratante se sirve del trabajo concreto y el contratista se hace cargo de 
darle forma a la relación. Los trabajadores pasan a estar bajo la dependencia del contratante, la relación entre ambos es la de la actividad material e intelectual, producto del quehacer (trabajo) concreto; es el contratante quien fija el contenido y la dirección del trabajo. El contratista (suministrador de trabajadores) es quien fija y paga los salarios, las horas extras, las cotizaciones previsionales, las indemnizaciones, el seguro contra riesgo de accidente y/o enfermedades laborales. Por estos servicios, arregla un precio con el contratante y su ganancia es la diferencia entre ese precio y el total de los costos de los servicios señalados. El contratista queda a cargo de los aspectos formales de la relación. La relación de subordinación y dependencia con la empresa usuaria se puede visualizar en indicadores tales como las instrucciones y controles, la vigilancia del desempeño de las funciones, el control de la asistencia. Estos trabajadores, ajenos a la empresa usuaria o contratante, reciben salarios diferentes y tienen derechos diferentes a los de los trabajadores de la empresa usuaria, aunque realicen las mismas tareas y trabajen unos junto a los otros. Los convenios que rigen para los trabajadores de la empresa, no tienen vigencia para los trabajadores temporarios (Cueva; Hughes, 2009).

De esta forma, las empresas reducen sus costos. Y sustituyen una relación laboral (y los conflictos que ella implica) por una relación comercial con otra empresa que se hará cargo de los problemas de la relación laboral. La empresa usuaria reduce los costos laborales, ya que al abastecerse de personal a través de la intermediación de un tercero, puede disponer y prescindir de él según sus necesidades. La tercerización precariza el empleo, ya que lo hace altamente inestable, reduce el nivel de remuneraciones y de la protección de la seguridad social y laboral. La subcontratación torna más frágiles las relaciones laborales individuales y colectivas, tanto en la empresa principal como en la subcontratista. Y produce una división entre los trabajadores "internos y externos". Se produce una dispersión del colectivo laboral (o conjunto de trabajadores) que trabajan para la misma empresa usuaria. Cabe señalar que en la práctica, estas formas de subcontratación no se presentan en formas puras sino en modalidades híbridas.

En la década del ' 80 , la dictadura otorgó al sector privado un rol preponderante para liderar el desarrollo nacional. Durante la etapa privatizadora y en lo que se ha dado en llamar la "revolución empresaria" desarrollada en los '80 y '90, las empresas trasnacionales tuvieron un rol decisivo en la promoción y generalización de las modalidades antes descriptas. En 1984 sólo existían 
tres (3) empresas de servicios temporarios; en 1986: 79; y a fines del años '90 habían aumentado a 150 empresas.

Estas modificaciones estructurales se profundizaron y consolidaron bajo los regímenes constitucionales que se sucedieron a partir de 1989.

Ante las constantes denuncias de los abusos laborales y la presión ejercida por las organizaciones sindicales, en el año 2002, el gobierno de la Concertación se vio forzado a presentar un proyecto de ley en el Parlamento que buscaba regular las formas de empleo “atípicas”. En enero de 2007, entró en vigencia la Ley sobre Subcontratación y Suministro de Personal, la que regula las "relaciones laborales triangulares", relaciones que responden a las estrategias del capital: algunas actividades son desplazadas hacia fuera de la empresa y son realizadas por otra empresa (distinta y ajena) que asumirá la ejecución de la tarea desplazada utilizando a sus propios trabajadores. A este fenómeno se lo conoce como triangulación laboral, en el que participan: 1- la empresa que externaliza, 2- la empresa que asume la actividad productiva externalizada y 3 - los trabajadores de la última empresa pero que de hecho prestan servicios para ambas empresas.

Sin embargo, esta Ley no sólo elude la raíz del problema: la expansión del subcontrato en las áreas propias del quehacer de la empresa, sino que ¡legaliza el suministro temporal de trabajadores! O, lo que es lo mismo, legaliza la precarización laboral al crear empresas de servicios transitorios y contratos de trabajo de servicios temporales.

Las denuncias y protestas de los trabajadores plantean que la Ley no supera problemas que aún hay en la subcontratación. Por un lado destacan las discriminatorias condiciones de trabajo y salariales que se distinguen entre los trabajadores subcontratados y los trabajadores de la empresa principal o usuaria, pese a que realizan el mismo trabajo. Es habitual que trabajadores propios y subcontratados compartan los mismos lugares de trabajo, horarios, las mismas faenas y las mismas condiciones de higiene y salud, pero los subcontratados perciben remuneraciones más bajas y no acceden a los beneficios establecidos en los contratos colectivos ya que no pertenecen a la empresa mandante en que se pautaron. Por otro, destacan la irrelevancia de negociar colectivamente con la empresa contratista ya que las decisiones económicas importantes las toma la empresa principal.

Las prácticas de subcontratación han ido acompañadas por nuevas formas de organización del proceso de trabajo y de utilización de la fuerza de 
trabajo, siendo uno de los fenómenos emergentes en el mundo laboral la aparición del "suministro de trabajadores”. Como plantea Silva (2007, p. 8), el suministro de trabajadores "representa la expresión más clara de la cosificación de la fuerza de trabajo, reducida simplemente a un factor más de producción”.

La práctica de la subcontratación se da principalmente en las Grandes Empresas, lo que hace de esta modalidad una estrategia productiva y laboral, pero que inunda progresivamente a toda la sociedad chilena.

\section{Transformaciones en la subcontratación}

Una de las características que fue adquiriendo la subcontratación es que va creciendo en las actividades principales de de las empresas. Pero, ¿cómo se define? Son aquellas que tareas, procesos o funciones cuya realización es consustancial o contribuye de forma decisiva a la producción de los bienes o la prestación de servicios que la empresa realiza y sin cuya realización se vería afectado el normal desarrollo de sus actividades.

Sintetizando, la subcontratación se aplica en las empresas de todos los tamaños y en todas las ramas de actividad. Pero es en la Gran Empresa donde se encuentra más extendida y es una estrategia fundamental de su organización productiva; así como también está mucho más generalizada en la construcción, la minería y el suministro de electricidad, gas y agua.

Es en el escenario de los primeros años del siglo actual, que emerge un nuevo actor: el trabajador subcontratista. Sus luchas y reivindicaciones ponen en evidencia a la vez que protagonizan los conflictos más importantes de la década que terminó.

\section{Los trabajadores de segunda}

Esta clasificación entre trabajadores no es una nimiedad. Las diferencias y desigualdades en las condiciones de trabajo y salariales, son cotidianamente vivenciadas. Recordemos que uno de los vacíos de la ley de subcontratación refiere a la igualación de salarios entre trabajadores que desempeñan tareas similares o iguales. A través de la tercerización laboral, se ha incrementado la desprotección del trabajador, quebrándose la forma tradicional de trabajo, basada en un empleo de tiempo completo, tareas ocupacionales bien definidas y la posibilidad de una carrera laboral a lo largo del ciclo vital. 
"Subcontratación, por tanto, es sinónimo de flexibilidad para las empresas, e inestabilidad para los trabajadores" (Contreras; Torres Cierpes, 2009, p. 77).

La sindicalización de trabajadores temporales es sumamente difícil, dado que su prioridad es mantener el trabajo, y saben que en las empresas no son bien vistos los trabajadores afiliados a un sindicato.

Además de esas condiciones de vida tienen que moverse entre las relaciones entre trabajadores que crea la política empresarial, que promueve la estratificación de la mano de obra en las propias unidades productivas, generando diferencias artificiales entre los trabajadores para que se produzcan conflictos entre ellos: ante las mismas faenas, y realizando la misma labor, los contratados reciben salarios mucho más bajos que los de planta y están sometidos a la inestabilidad laboral permanente. La empresa también promueve la existencia de sindicatos paralelos, a cuyos agremiados los beneficia con mejores condiciones.

\section{La Importancia del cobre en Chile}

Al presentar al Congreso Nacional esta reforma constitucional, estamos afirmando que no estamos dispuestos a tolerar más esta situación y que de ahora en adelante en nuestra propia Carta Fundamental, quedará establecida nuestra decisión de que las riquezas chilenas sean de los chilenos y para los chilenos, que basados en ella construirán una nueva vida y una nueva sociedad. Sabemos que todos los pueblos libres del mundo nos acompañarán en esta tarea. (Salvador Allende) ${ }^{8}$

La principal riqueza natural y recurso de exportación de Chile en el siglo XX y lo que va del XXI es el cobre. Esta explotación tiene una fuerte impronta neocolonial, ya que desde el inicio del siglo pasado los principales yacimientos cupríferos eran explotados -en una suerte de sistema de enclave- por capitales norteamericanos. La relación histórica entre el Estado chileno y los capitales extranjeros ha estado determinada por el usufructo asimétrico de su

8 Mensaje al Congreso Nacional al presentar el Proyecto de Reforma Constitucional para la nacionalización del Cobre. 
riqueza mineral. Esta relación de expoliación tuvo empero, su etapa reivindicativa a mediados del siglo XX, cuando comienzan a cristalizar en la opinión pública las ideas de soberanía de su principal riqueza mineral. En 1964, con la presidencia de Eduardo Frei Montalva se lleva adelante una política reformista, cuya línea económica incluye una política cuprífera conocida como “chilenización del cobre". ${ }^{9}$ Se pone en marcha la "nacionalización pactada": la adquisición del 51\% de las acciones de los yacimientos, primer paso a la nacionalización integral de la extracción de cobre. Al finalizar el gobierno de Frei Montalva, dos candidatos que compiten por la presidencia impulsan en sus respectivas campañas la estatización de la producción: Radomiro Tomic y Salvador Allende. El triunfo de la Unidad Popular hizo posible que el 11 de julio de 1971 se aprobase en el Congreso Nacional, y por voto unánime, la enmienda constitucional que nacionalizaba totalmente el cobre (Ley $\mathrm{N}^{\circ} 17.450$ ) que se convertía así -en palabras del propio Allende- en "el sueldo de Chile", ${ }^{10}$ una suerte de "segunda independencia". En ese pequeño territorio se encuentran Chuquicamata, el yacimiento más grande del mundo a tajo abierto, y El Teniente, que con sus 2400 kilómetros de galerías es la mina subterránea más grande del mundo. Las exportaciones mineras representan un $61 \%$ de las exportaciones totales chilenas, ${ }^{11} \mathrm{y}$ dentro de este sector de la economía, el 86,6\% corresponde al cobre (Servicio Nacional de Geología y Minería, 2012) generando cuantiosos recursos para el país, que también resultaron fundamentales para el funcionamiento de la economía durante la dictadura militar pese a que, como señala Borón (2000, p. 149-183), en los documentos del Banco Mundial, en los que se elevaba el caso chileno a la categoría de "modelo" a imitar, se pasaba por alto este dato. ${ }^{12}$

9 En 1967 se dictó la Ley N 16.425, que autorizó la creación de sociedades mixtas entre el Estado de Chile y las compañías extranjeras productoras de cobre.

${ }^{10}$ El caso excepcional de la riqueza cuprífera chilena reside en que, si bien Chile tiene sólo el 0,5\% del territorio mundial, allí se localiza el $40 \%$ de las reservas mundiales de cobre. Salvador Allende llamó al cobre "el Sueldo de Chile", ya que planteaba financiar con él gran parte del gasto social, por lo que denominó al día 11 de julio de 1971 como 'Día de la Dignidad y de la Solidaridad Nacional'.

${ }^{11}$ El economista Orlando Caputo establece una comparación reveladora de la importancia estratégica de este mineral para Chile: en términos mundiales Chile es al cobre lo que la OPEP al petróleo. Sólo que la OPEP está conformada por 11 países (Caputo; Galarce, 2007b).

${ }^{12}$ Según Naomi Klein (2007), Chile evitó el colapso económico en los años '80 gracias a que la dictadura no privatizó CODELCO, empresa que le continuó generando el $85 \%$ de los ingresos por exportaciones.

Horizontes Antropológicos, Porto Alegre, ano 19, n. 39, p. 99-124, jan./jun. 2013 
En 1976, la dictadura crea un subterfugio ${ }^{13}$-mediante una simple leypara entregar en dominio privado las minas de cobre de todo el país a capitales privados extranjeros: la figura de "concesión plena”. A pesar que la Constitución estipulaba que el Estado tiene el "dominio absoluto, exclusivo, inalienable e imprescriptible de todas las minas", la "Concesión Plena” garantiza a estos capitales un usufructo en mejores condiciones aún que la propiedad privada. La concesión plena privilegia, garantiza y mejora los derechos al titular del dominio privado,

sin plazo de término, irrevocable, inmodificable, y en caso de expropiación, con pago del valor comercial del yacimiento, no sólo de las inversiones, sino también el pago de los flujos futuros. O sea, Chile tendría que pagar los yacimientos de cobre, incluyendo los subproductos, hasta el momento en que se agoten. (Caputo, 2008a).

Esta operación se realiza mediante la empresa estatal Corporación Nacional del Cobre de Chile (CODELCO), quien se reserva un 30\% del total de las explotaciones para propiedad del Estado y un $70 \%$ pasa a virtual propiedad de compañías extranjeras. ${ }^{14}$ Más tarde, la dictadura garantiza el presupuesto de las Fuerzas Armadas de Chile mediante la normativa que establece que el $10 \%$ de las ventas de CODELCO al exterior deben ser depositadas en dólares en el Banco Central de Chile, con el objeto de financiar sus compras militares. ${ }^{15}$

Las grandes inversiones extranjeras se produjeron durante los gobiernos de la Concertación siendo el sector minero el que concentra la mayoría de ellas, concretándose de esta forma el proceso de "desnacionalización del cobre”, perdiendo Chile autonomía y soberanía incluso para decidir qué cantidad de cobre producir. Y se ha apoyado y fortalecido desde el gobierno a las grandes empresas mineras mundiales que compiten con CODELCO en el mercado mundial. La participación de la cuprífera estatal en el mercado

13 Radomiro Tomic dijo que la concesión plena fue tramitada y aprobada en secreto (Caputo, 2008a).

${ }^{14}$ La Dictadura hace desconocer así a la propia Constitución de Chile. Los sucesivos gobiernos democráticos, desde 1990 hasta el presente, han continuado con esa inconstitucionalidad.

15 Analistas calculan que, entre 1990 y 2007, CODELCO ha entregado a las FFAA más de 7.500 millones de dólares, lo cual estaría representando casi el 70\% de todas las inversiones que esa compañía estatal ha realizado durante ese periodo. 
mundial de cobre aumentó de 8,2\% en 1973 a 13,4\% en 1990, disminuyendo a partir de ese año. La participación de las empresas privadas, aumentó del 1,6\% en 1973 a 24, 2\% en 2006: es decir, CODELCO pierde participación en el mercado mundial del cobre y la gana las empresas privadas, particularmente extranjeras. ${ }^{16}$ En el año 2010, CODELCO produce excedentes de 5.799 millones de dólares, casi un 47\% más respecto de los 3.948 millones obtenidos en el 2009. Los excedentes corresponden a los resultados antes de impuestos a la renta y de la Ley 13.196, que grava con el $10 \%$ al retorno por la venta en el exterior de cobre y subproductos propios. Este monto sólo es superado por los registrados en 2006 y 2007. Los resultados del 2010, estuvieron influidos, principalmente por la fuerte alza del precio internacional del cobre y del molibdeno (Corporación Nacional del Cobre, 2010).

En 2011, Chile seguía siendo el primer productor mundial de cobre.

La "desnacionalización del cobre" ha sido un proceso que se dio en forma paralela al fraccionamiento de los procesos de trabajo en empresas contratistas y subcontratistas. ${ }^{17}$

\section{La precariedad laboral en el sector minero}

La medición de la subcontratación en la actualidad es difícil de estimar, por la complejidad del fenómeno. La excepción está dada por la minería, ya que por disposición del Servicio Nacional de Geología y Minería, lleva un registro completo de la cantidad de empresas como de trabajadores ocupados de empresas contratistas y mandantes.

La serie de Encuestas Laborales de la Dirección del Trabajo muestra cómo ha crecido la subcontratación laboral en el sector minero: en 1999 el $37 \%$ de las empresas del sector subcontrataban, en 2002 y 2004 el porcentaje de empresas ascendía a más del 63\%.

En 2011, había 707 empresas mandantes, y 3235 contratistas: el 82\% de las empresas del sector eran contratistas.

\footnotetext{
16 Para dimensionar la importancia de la minería cuprífera y las elevadas ganancias que obtienen las empresas extranjeras, mencionemos que por ejemplo, en el año 2005, las 10 grandes empresas mineras privadas obtuvieron ganancias equivalentes a la suma del presupuesto de dos ministerios: el de Salud y el de Educación (Caputo; Galarce, 2006, 2007c).

17 Muchos políticos participan en la propiedad de estas empresas (Caputo; Galarce, 2007a).
} 
La minería, particularmente las estatales CODELCO y ENAP, son de las primeras promotoras de la subcontratación; y en la actualidad, este sector muestra los mayores niveles tanto respecto a la cantidad de empresas que utilizan esta modalidad de empleo como de empresas contratistas que operan para ellas. En 1997, se contaban 403 empresas mandantes y 919 contratistas en el sector minero. Una década después, las empresas mandantes existentes eran 471 mientras que las contratistas habían aumentado a 3628.

Las labores que realizan los trabajadores tercerizados incluyen desde actividades secundarias o anexas de casinos, seguridad, transporte, hasta operaciones estratégicas, como las faenas de extracción y procesamiento de la roca. Si consideramos el número de trabajadores, observamos que mientras el número de trabajadores subcontratados crece sostenida y rápidamente, los trabajadores de empresas mandantes disminuyen lentamente.

En 1982, la relación era de 187 trabajadores de planta por cada tercerizado, en 2006 había casi 2 tercerizados por cada trabajador de planta.

\section{Subcontratación en la Corporación Nacional del Cobre}

Un fenómeno digno de destacar en el mundo de la subcontratación es el papel jugado por CODELCO. Desde principios de los años '80, la subcontratación ha mostrado un sostenido crecimiento. La subcontratación, a partir de los gobiernos de la Concertación, mantuvo una tendencia alcista, inversamente proporcional a la dotación de trabajadores propios, la que muestra una importante reducción.

Durante la década pasada, el aumento significativo de la dotación de trabajadores subcontratados encontraría una de sus causas en la decisión de aumentar en aproximadamente un 30\% la producción de El Teniente, lo que llevó a incrementar especialmente la cantidad de “contratistas de operación”, que son aquellos que realizan actividades propias del núcleo principal de la empresa: la extracción y procesamiento del cobre.

\section{Los trabajadores subcontratistas}

La historia de los trabajadores de El Teniente, como así también la tradición sindical que construyeron, ha cambiado conjuntamente con los cambios 
que ha sufrido Chile. El sindicalismo actual, presenta grandes diferencias con el de hace 50 años.

CODELCO no fue ajena a la subcontratación que a partir de los años ochenta, se implementaba en Chile, cuando se crea el Plan Laboral:

El año '80, cuando se crea el Plan Laboral, junto a eso se eliminan varias leyes; dos leyes que te regulaban el acceso de los contratistas al área productiva. Ahí se abre el giro o sea las empresas pueden hacer cualquier trabajo. (Ex dirigente sindical subcontratista). ${ }^{18}$

Como explicamos anteriormente, lo relevante de este proceso es que las empresas podían externalizar labores que le eran o son propias a la empresa.

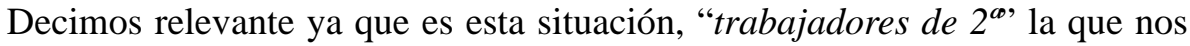
permite comprender las luchas y movilizaciones de los trabajadores subcontratistas en la última década, ya que una de sus demandas principales era la búsqueda de reconocimiento como trabajadores de la empresa para la cual trabajaban: CODELCO.

En el año '87 se hace la huelga. Esa es una huelga que yo creo que marcó. Tomaron detenidos a los dirigentes, se amplia mucho más la lista negra y fue la primera manifestación pública en la ciudad de Rancagua. Estamos hablando de 400 trabajadores. Fue la primera vez que se vieron tanquetas en Rancagua, en la carretera del cobre nos disolvieron [...] los viejos nos bajamos en Nogales y de ahí marchamos hasta Rancagua. Eso fue lo más fuerte que se hizo en ese período, que fue una huelga ilegal contra el consorcio. (Ex dirigente sindical subcontratista). ${ }^{19}$

En 2003, se produce una huelga que denuncia las condiciones de trabajo en el sector cuprífero: son despedidos 200 trabajadores. En diciembre de 2003, los trabajadores agrupados en SITECO, hacen visible la magnitud del proceso que estaban gestando, al entregar un pliego de peticiones a la Empresa CODELCO, acompañado de un paro de "brazos caídos".

La feroz represión tuvo una consecuencia no deseada por parte del Capital: los trabajadores tomaron conciencia sobre la necesidad de una

${ }^{18}$ Citado en Torres Cierpe et al. (2010, p. 120).

${ }^{19}$ Citado en Torres Cierpe et al. (2010, p. 121). 
organización nacional. Así, en 2004 se crea en Caldera, la Coordinadora Nacional de Trabajadores Contratistas.

El 4 de enero de 2006, los trabajadores subcontratistas de Andina, El Teniente, Norte y Ventana, ante la negativa de la empresa a pagar un bono por el alto precio que había tenido el cobre, inician una huelga de carácter indefinido.

Dada la magnitud de trabajadores subcontratistas, la presión a la empresa se hace sentir ya que comenzó a tener mermas en la producción y los ingresos.

El gobierno del entonces presidente Lagos, convoca a una mesa de negociación, donde están representados CODELCO, las empresas contratistas y los trabajadores tercerizados.

El logro de esta movilización fue la promulgación de la ley que regula los aspectos de la subcontratación, la que se pone en marcha en enero de 2007.

En mayo del 2007, la Coordinadora anuncia posibles medidas de fuerza ya que la Ley de Subcontratación no se estaba cumpliendo. Uno de los hechos más significativos y de mayor trascendencia, ocurrió en el mes de junio, cuando la Coordinadora Nacional de Trabajadores Subcontratistas, reunida en Machalí, se convierte el 8 de junio en la Confederación de Trabajadores del Cobre (CTC). Una vez constituida, los trabajadores deciden iniciar una huelga ante el incumplimiento de los acuerdos alcanzados, acción de lucha que será nominada y recordada con posterioridad como "la huelga histórica" de 37 días. Entre el 25 de junio y el 31 de julio, la paralización de las tareas fue generalizada. Las demandas incluían beneficios en salud, educación, vivienda y compensaciones económicas, además del cumplimiento de la ley.

La mediación del obispo de Rancagua, Alejandro Goic, no sólo fue importante para lograr un acuerdo, sino que puso en 1er. plano a nivel nacional, el debate sobre el sueldo ético.

En esta ola de protestas, se sucederá el conflicto, cuyo origen se encuentra en la negativa de CODELCO a internalizar como trabajadores de planta a 5000 trabajadores subcontratistas. Desde enero del 2008, se producen una serie de huelgas aisladas convocadas por la CTC, hasta que a partir del 16 de abril y hasta el 6 de mayo, se iniciaron una serie de protestas nacionales, provocando el otro gran conflicto que protagonizó el sector cuprífero en la década. El mismo llega a su fin cuando los trabajadores aceptan un bono de 500.000 pesos y un plazo de 6 meses para que CODELCO cumpliera con la Ley. Esta vez, la mediación estuvo a cargo del entonces Ministro del Interior, 
E. Perez Yoma; del Ministro de Trabajo, Osvaldo Andrade y del Presidente de la Central Unitaria de Trabajadores, Arturo Martínez.

La historia de los trabajadores subcontratistas de El Teniente, puso de manifiesto a nivel nacional, la precariedad e inseguridad a la que están sometidos los trabajadores tercerizados en general, siendo los mineros unos de los protagonistas más importantes de las luchas sociales de la última década y haciendo visible la profundización y agudización de la desigualdad estructural que implicó la restructuración capitalista en Chile, a partir de la Dictadura Pinochetista.

No es casual que sea en la Gran Minería dónde encontramos a los protagonistas de las luchas sindicales en Chile. Estas prácticas constituyen, forman parte, y/o son herederas de una importante tradición construida por los trabajadores del cobre, al mismo tiempo que se renuevan en sus prácticas de organización y acción. Los trabajadores tercerizados se organizan y actúan a nivel interempresa, adquiriendo rápidamente formas organizativas a nivel nacional. Sus reclamos, superan la simple reivindicación salarial dando paso a la demanda se ser respetados como trabajadores, la que incluye estabilidad en el trabajo, igualdad de salarios ante el mismo trabajo e igualdad de trato: dejar de ser "trabajadores de segunda". Sus demandas y reclamos se realizan en espacios públicos, siendo característico el interrumpir, el lograr detener la producción a través de bloqueos de caminos: modalidad para lograr hacer visible la explotación y discriminación a la que son sometidos.

La organización sindical minera refleja desde hace décadas la importancia que tiene la explotación del cobre para el Chile, "el sueldo de Chile". Es por ello que las prácticas y organización sindical de los trabajadores cupríferos, son parte de una larga historia que muchos tratan de olvidar u ocultar, para así naturalizar las deshumanizadas condiciones de trabajo y la explotación a la que aún hoy, son sometidos los trabajadores mineros. Una de las últimas lamentables muestras de esta situación, falta de seguridad y de fiscalización, se evidenció en el "accidente" que mantuvo a 33 mineros durante 70 días atrapados bajo tierra en la mina San José de Copiapó, en la región de Atacama. Pese a ese llamado de atención, que dio la vuelta al mundo, y que del éxito del rescate se quiso apropiar el gobierno para mostrar el cuidado que tiene por la vida de los trabajadores, a los pocos días, una explosión en el yacimiento Los Reyes, cercano a Copiapó, causó la muerte de dos trabajadores. Javier Castillo, presidente del sindicato San Esteban, declaró: 
Pensamos que habría un antes y un después del accidente de los 33, pero esto está igual, no existe fiscalización y hay empresarios que operan fuera de la ley, matan a trabajadores y toman un avión como si nada.

Las huelgas que han protagonizado en los últimos años los trabajadores subcontratados de la gran minería revelan que la Ley de Subcontratación no ha cumplido el objetivo de disminuir el conflicto entre trabajadores subcontratados, empresas subcontratistas y grandes empresas mineras.

Destacamos nuevamente que, a pesar de las dificultades de sindicalización que la reestructuración capitalista instituyó en Chile, desde finales de los años ochenta y primera mitad de los años noventa, diversas franjas de trabajadores, comenzaron a organizarse, aunque sea en forma embrionaria, para resistir a las nuevas embestidas del Capital.

La emergencia de un polo de resistencia en la minería se da desde un núcleo de lucha inesperado por el Capital: los sindicatos de obreros tercerizados, periféricos respecto a los agrupamientos históricos de la clase obrera chilena (Cueva; Hughes, 2009).

Pese a todos los intentos por desplazar el conflicto capital-trabajo al conflicto trabajo-trabajo (nos referimos al supuesto conflicto entre trabajadores de adentro y trabajadores de afuera), la contradicción principal, por más que se la quiere disfrazar, continua siendo capital-trabajo.

\section{A modo de cierre}

La clase trabajadora chilena tiene claro, y ese es el mayor legado histórico de la misma, que los avances económicos y sociales de los sectores populares han sido conquistados y defendidos por los propios trabajadores, en este sentido, podemos hablar de una clase autónoma. Coincidimos con Salazar y Pinto (1999) cuando dicen que los sectores populares en Chile han organizado un proyecto histórico de largo plazo, contra hegemónico del proyecto oligárquico y en los márgenes del poder, en ese proyecto el pueblo habría buscado oponerse activa y prácticamente, a las tendencias marginadoras de la élite. Salazar y Pinto se atreven a ir más lejos cuando sugieren que en las "etapas formativas” del bajo pueblo se evidenciaría la existencia de un proyecto histórico de acumulación productivista, marginal, llevado a cabo por "empresarios populares” y legitimado éticamente por su carácter solidario y humanitario. 
En estos momentos la clase trabajadora chilena tiene que enfrentarse con las distintas estrategias de la hegemonía para reproducirse con el menor costo posible, con la renovación engañosa de la misma y con su propio estado de desarrollo, que la ubica utilizando métodos que fueron pensados para otros momentos históricos. Pensamos que en este marco debemos entender a los acontecimientos que se producen en el campo de la conflictividad laboral, como rebeliones antes que como trabajo sistemático de una clase que procede acumulando poder. ${ }^{20}$ Pero, también pensamos que se están abriendo nuevos espacios de ejercicio político dentro de la izquierda chilena, espacios de necesario debate, a partir de los cuales, seguramente se van a empezar a dar las condiciones que permitan la constitución de sujetos emancipados.

\section{Referencias}

AGACINO, R. Pasado y presente: los trabajadores una vez más. Ciencias Sociales Hoy: Blog de Eduardo Aquevedo S. 2008. Disponible en: <http:// jaquevedo.blogspot.com/2008/06/los-trabajadores-una-vez-mas-rafael. html>. Acceso: 1 jun. 2010.

BORÓN, A. Quince años después: democracia e injusticia en la historia reciente de América Latina. In: BORÓN, A. Tras el búho de minerva: mercado contra democracia en el capitalismo de fin de siglo. Buenos Aires: Fondo de Cultura Económica, 2000. p. 149-183.

CAPUTO, O. El cobre: la única solución la renacionalización. Rebelión, 21 sept. 2008a. Disponible en: <http://www.rebelion.org/noticia.php?id=72984>. Acceso: 30 ago. 2012.

CAPUTO, O. Chile, de nuevo uno de los países más afectado por las crisis. Rebelión, 14 nov. 2008b. Disponible en: <http://www.rebelion.org/noticia. php?id=75798> . Acceso: 30 ago. 2012.

${ }^{20}$ Esto es parte del debate actual: Entrevista con Manuel Acuña Asenjo. Registro de campo, Santiago, noviembre, 2010. 
CAPUTO, O.; GALARCE, G. Lo que todos callan: las ganancias de las empresas extranjeras en el cobre. Rebelión, 24 abr. 2006. Disponible en: <http://www.rebelion.org/noticia.php?id=30419> . Acceso: 30 ago. 2012.

CAPUTO, O.; GALARCE, G. Trabajo precario en el cobre. Rebelión, 26 jun. 2007a. Disponible en: <http://www.rebelion.org/noticia.php?id=52765>. Acceso: 30 ago. 2012.

CAPUTO, O.; GALARCE, G. De la nacionalización del cobre por Allende a la desnacionalización por la dictadura y la Concertación. Observatorio Latinoamericano de Conflictos Ambientales, 11 jul. 2007b. Disponible en: $<$ http://www.olca.cl/oca/chile/mineras/mineras015.htm>. Acceso: 30 ago. 2012.

CAPUTO, O.; GALARCE, G. Sindicatos de planta y trabajadores de empresas contratistas de Codelco. Rebelión, 12 jul. 2007c. Disponible en: <http://www. rebelion.org/noticia.php?id=53423>. Acceso: 30 ago. 2012.

CASTEL, R. La metamorfosis de la cuestión social. Buenos Aires: Paidós, 1997.

CONTRERAS, C.; TORRES CIERPE, J. Los trabajadores subcontratistas de Bosques Arauco y CODELCO: ¿Un movimiento en vías de politización?. Revista Mad, n. 20, p. 71-89, 2009.

CORPORACIÓN NACIONAL DEL COBRE. Memoria anual. 2010. Disponible en: <http://memoriaanual2010.codelco.cl/>. Acceso: 1 jul. 2011.

CORTÉS MORALES, A. A reprimarização do modelo de desenvolvimento chileno. Rio de Janeiro: IUPERJ, 2009.

CUEVA, D.; HUGHES, M. F. Trabajo subcontratado y ¿nuevas? Formas de organización en el centro productivo nacional. El caso de los mineros del cobre en Chile. In: ACTAS DEL PRIMER CONGRESO NACIONAL "Protesta Social, Acción Colectiva y Movimientos Sociales”. 2009. Soporte digital. 
FAZIO, H.; PARADA, M. Veinte años de política económica de la Concertación. Santiago: LOM Ediciones, 2010.

FRIEDMAN, M. Capitalismo y libertad. Madrid: Rialp, 1966.

HOLLOWAY, J. La rosa roja de Nissan. Cuadernos del Sur, Buenos Aires, n. 6, p. 42-64, 1987.

HUGHES, M. F. La importancia del cobre en Chile. In: LISCHETTI, M. (Coord.). Los conflictos sociales en el Chile del siglo XXI: nuevas expresiones de la lucha de clases. Buenos Aires: Biblos, 2012. p. 27-40.

HUGHES, M. F.; LISCHETTI, M. Conflictividad laboral entre los trabajadores forestales en el sur chileno. In: LISCHETTI, M. (Coord.). Los conflictos sociales en el Chile del siglo XXI: nuevas expresiones de la lucha de clases. Buenos Aires: Biblos, 2012. p. 105-141.

KLEIN, N. La doctrina del shock: el auge del capitalismo del desastre. Barcelona: Paidós, 2007.

MINISTERIO DE PLANIFICACIÓN Y COOPERACIÓN. División social. Departamento de Estudios Sociales. Resultados de la VII Encuesta de Caracterización Socioeconómica Nacional (CASEN 1998): documento n. 1: pobreza y distribución del ingreso en Chile 1990-1998. Santiago, 1999. Disponible en: <http://www.archivochile.com/Chile_actual/11_econom/ chact_econ0007.pdf >. Acceso: 30 ago. 2012.

PETRAS, J. La metamorfosis de los intelectuales latinoamericanos. Estudios Latinoamericanos, n. 5, p. 81-86, jul./dic. 1988.

SALAZAR, G.; PINTO, J. Historia Contemporánea de Chile. Santiago: Arcis-Lom, 1999.

SERVICIO NACIONAL DE GEOLOGÍA Y MINERÍA. Anuario de la minería de Chile 2011. Santiago, 2012. Disponible en: <http://www.sernageomin.cl/ pdf/mineria/estadisticas/anuario/anuario_2011.pdf>. Acceso: 30 ago. 2012. 
SILVA, C. La subcontratación en Chile: aproximación sectorial. 2007. Disponible en: <http://www.estudiosdeltrabajo.cl/wp-content/ uploads/2008/11/la-subcontratacion-en-chile-c1-silva.pdf >. Acceso: 5 mar. 2009.

TORRES CIERPE, J. et al. Tradición sindical en El Teniente: un recorrido por más de un siglo de historia. Santiago: Consejo Nacional de la Cultura y las Artes, Gobierno de Chile, 2010.

Recebido em: 31/08/2012

Aprovado em: 17/01/2013 